\title{
O Desafio Chinês Para A África
}

Resenha recebida em 11/08/2020 e aprovada em 07/12/2020.

Magno Klein ${ }^{I}$

A presença chinesa no continente africano impressiona. Ela é sentida no financiamento de grandes obras de infraestrutura, na atuação de empresas de pequeno e grande porte, na circulação de migrantes e mesmo no uso de tropas militares para controlar crises regionais. Essa presença é ainda mais evidente no âmbito econômico: quase todas as nações africanas hoje têm na China seu mais importante parceiro comercial. A presença chinesa na África é o tema do estudo da pesquisadora finlandesa Anja Lahtinen (2018). Seu livro analisa as características políticas, econômicas, sociais e culturais da atuação chinesa no continente africano por meio da análise de entrevistas e fontes primárias de diversos tipos, coletadas em suas pesquisas de campo.

Em geral, as pesquisas acadêmicas a respeito das relações sino-africanas reconhecem os benefícios da parceria para as nações africanas, mas crescentemente colocam em questão se ela é tão vantajosa para a África quanto o é para a China ${ }^{\mathrm{II}}$. Entre os principais riscos, é normalmente citada a vulnerabilidade africana no âmbito do comércio, uma vez que as exportações em direção à China são compostas de poucos produtos primários. Além disso, a China é comumente criticada pela falta de transparência em seus acordos de cooperação, pelo apoio a regimes repressivos e pela falta de preocupação ambiental. Empresas chinesas são acusadas de concorrência predatória, de oferecer baixas condições de trabalho e mesmo de importar mão de obra ao invés de usar trabalhadores africanos.

Lahtinen (2018) reconhece que a estratégia chinesa para o continente africano é auto-interessada e movida, sobretudo, para a garantia de insumos para sua indústria (como minérios e petróleo), de mercado consumidor para suas exportações e de apoio a sua agenda multilateral (em especial em temas sensíveis como a independência do Tibete e de Taiwan). Entretanto, para a autora, a parceria também oferece benefícios. Isso é reforçado na atenção dedicada pelo livro ao tema do soft power. Em seus primeiros capítulos, é feita uma apresentação geral das relações sino-africanas e, nos dois capítulos finais subsequentes, analisam-se as ações de soft power em geral ${ }^{\mathrm{III}}$ e da diplomacia cultural em particular ${ }^{\mathrm{IV}}$, que são o tema de maior interesse da pesquisadora. O argumento central de Lahtinen (2018) é de que o continente africano tem grande importância na estratégia de inserção global chinesa e por isso sua estratégia para a região é diversificada, atuando em múltiplas agendas e estratégias de cooperação. Desse modo, Lahtinen matiza a crítica imperialista tão comum em grande parte das pesquisas nessa agenda.

Para entender a importância do continente africano na política internacional chinesa, o livro reconstitui a trajetória histórica da parceria entre China e África. O texto remonta ao primeiro período de aproximação nos anos 50 e 60 , inspirado pelas lutas de libertação colonial. Nesse sentido, a primeira embaixada chinesa no continente foi aberta no Cairo em 1954 e, no final dos anos 1970, a China já havia estabelecido relações diplomáticas com 44 dos 50 Estados africanos independentes. No final dos anos 1970, esse processo foi revertido: durante o governo de Deng Xiaoping, a China entrou numa fase de reformas econômicas pró-mercado e se aproximou dos países ocidentais. 


\section{O DESAFIO CHINÊS PARA A ÁFRICA}

MAGNO KLEIN

Porém, essa aproximação foi comprometida com a repercussão, no Ocidente, da repressão às manifestações na Praça da Paz Celestial em 1989. Foi nesse contexto que a China se voltou para a África buscando fortalecer velhas relações e iniciar novos projetos. Naquele momento, o continente africano era percebido pelo sistema internacional como local de problemas, graves violações de direitos humanos e crises constantes, e com poucas exceções estava fora do radar dos investimentos dos países centrais, cuja presença na região era focada em ajuda humanitária. O perfil da parceria sino-africana deixou então de ser marcadamente ideológico para ser dominado por interesses econômicos. Desde esse momento, a importância da China para o continente é crescente e, em 2012, o país se tornou o mais importante parceiro comercial africano.

$\mathrm{Se}$ as nações ocidentais impunham condicionalidades e sanções contra determinados países, a China se interessava por acordos mesmo com Estados-párias, oferecendo acordos pragmáticos e sem condicionalidades. Além da agenda comercial, o país tem contribuído para a estabilidade regional com o envio de militares para tropas de paz da ONU e também tem apoiado a institucionalização de mecanismos regionais de segurança, além de ser um parceiro relevante em projetos de cooperação para o desenvolvimento e de financiar alguns dos maiores projetos de infraestrutura do continente.

Lahtninen (2018) acredita que as ações chinesas na África estão muito mais envoltas em estratégias de soft power do que se costuma imaginar, e defende que se preste mais atenção às ações de diplomacia cultural do país, como o estímulo ao intercâmbio estudantil, a abertura de unidades do Instituto Confúcio e a promoção de elementos da cultura chinesa tradicional, como artes marciais e acupuntura.

A autora se detém na percepção pelos africanos desse soft power, concluindo que a estratégia chinesa na África carece de uma identidade cultural sedutora: seus valores e ideias não seriam tão atraentes quanto os ocidentais. Faltariam, ao soft power chinês, "valores universais". Segundo dados de pesquisas de opinião pública feitos pelo Instituto Afrobarometro, os africanos desconfiam da presença chinesa e sentem que os chineses não respeitam sua cultura ${ }^{\mathrm{V}}$. É disseminado entre as populações o medo de que as empresas chinesas prejudiquem negócios locais, ameacem empregos, extraiam recursos naturais do continente e se apropriem de territórios (land grabbing). Todos esses receios põem em xeque o discurso oficial da atuação chinesa como qualitativamente melhor do que a Ocidental ${ }^{\mathrm{VI}}$.

Ao colocar em questão o que atrai os países africanos na China, a grande contribuição do texto de Lahtinen é apresentar a África com poder de agência e capacidade para enfrentar os desafios dessa parceria. Desse modo, o texto se distancia do tom mais alarmista presente em outros estudos marcados pela preocupação com uma "nova partilha da África"VII ou um "neo-neo-colonialismo"VIII . Seu estudo também tem a qualidade de fugir da visão caricata, ainda que comum, de que a cooperação proposta pelo Ocidente é mais altruísta e por isso mais benéfica para a África do que se relacionar com uma China autoritária e interessada exclusivamente em benefícios pragmáticos. A aproximação junto à China amplia as opções das nações africanas e coloca um desafio considerável às práticas até então adotadas pelo Ocidente na região.

Desde 2000, essa parceria é reforçada nos encontros anuais do Fórum ChinaÁfrica (conhecido como FOCAC). No encontro de 2006, foi lançada a declaração "Política da China para a África", em que os países definiram como principais objetivos para a cooperação o benefício mútuo e a prosperidade compartilhada. A versão atualizada do documento de 2015 apresentava o compromisso de superar os gargalos da infraestrutura e do desenvolvimento de recursos humanos no continente. Prometiam-se 


\section{O DESAFIO CHINÊS PARA A ÁFRICA \\ MAGNO KLEIN}

"resultados práticos" em contraponto às exigências dos países ocidentais por democracia e adoção de políticas públicas. Em 2013, foi lançada a Iniciativa "Um Cinturão, Uma Rota", com a promessa de investimentos em portos, oleodutos, estradas e ferrovias conectando a China a 60 países da Ásia, Europa, Oceania e África. Ela é uma das ações mais ousadas da nova fase da política externa chinesa e não estão claros os impactos desses investimentos para o continente africano, em especial quanto ao risco de maior dependência em relação à economia e política chinesas.

O estudo da presença chinesa na África também evidencia as idiossincrasias das mudanças recentes da política externa chinesa. Até então o país nutria uma estratégia de desenvolvimento econômico amparada em uma política externa de baixo perfil. Durante o atual governo de Xi Jinping (2013), o país tem assumido um perfil mais incisivo na defesa de seus interesses estratégicos e dado mais ênfase a ferramentas de hard power na defesa de seus interesses. Além de ter ficado mais evidente o interesse em contribuir como um ator responsável no trato das principais questões internacionais. No momento em que os Estados Unidos do governo Donald Trump abandonam o acordo do clima de Paris e inviabilizam outros espaços multilaterais, a China vem se mostrando disposta a assumir o vácuo da liderança global e sua presença no continente africano pode ser um balão de ensaio para entender as novas configurações de poder no sistema internacional, com seu apoio em questões de paz e segurança, por exemplo.

A presença chinesa trouxe o continente africano para os holofotes da economia global, mas a região vem sofrendo com a crise financeira iniciada em 2008, que afetou não só os fluxos de investimento na região, mas também suas exportações, em particular para a China. Lançado em 2018, o livro de Lahtinen contribui para a reflexão a respeito desse novo momento. Até então, o crescimento econômico do continente e a grande oferta de investimentos foram em boa parte garantidos pela parceria chinesa. Agora, a nova fase reforça a necessidade de reduzir a dependência em relação à China e buscar outras fontes para o crescimento econômico.

\section{Notas}

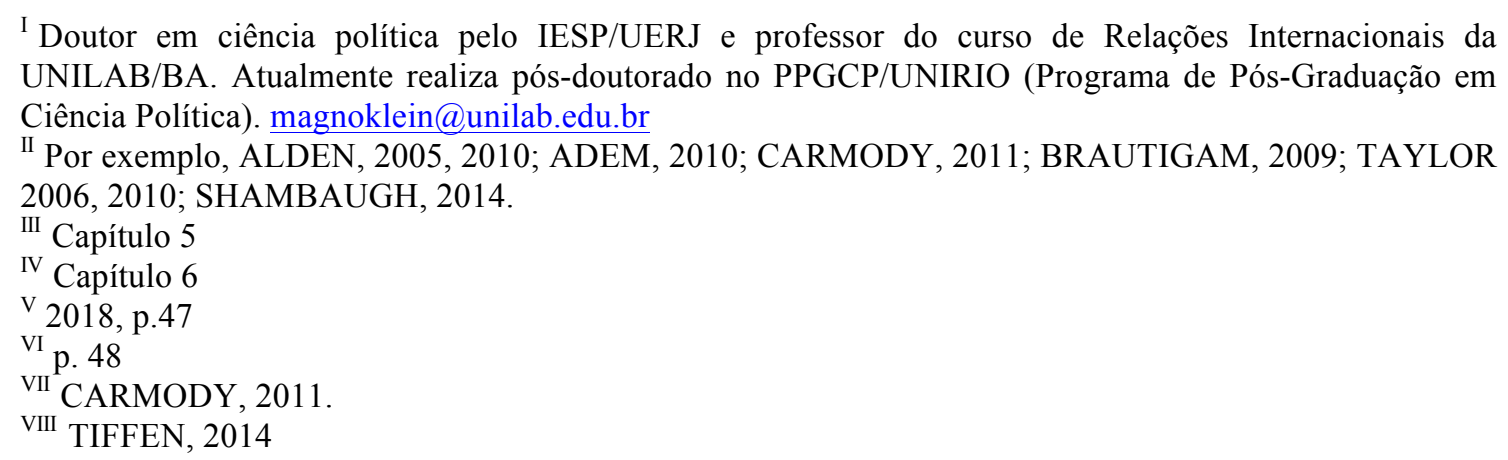

\section{Referências}

ADEM, Seifudein. The Paradox of China's Policy in Africa. African and Asian Studies, 9, 334-355. Leiden: Brill, 2010. https://doi.org/10.1163/156921010X515996

ALDEN, Chris. China in Africa. Survival: Global Politics and Strategy, 47(3), 147164. https://doi.org/10.1080/00396330500248086. 2005 
ALDEN, Chris. China's New Engagement with Africa'. In: ROETT, Riordan; PAZ, Guadalupe (ed.). China's Expansion into the Western Hemisphere: Implications for Latin America and the United States. p. 213-35. Brookings Institution Press, 2010. ISBN-13:978-0-8157-7553-9

ANJA LAHTINEN, China's Diplomacy and Economic Activities in Africa: Relations on The Move. Cham: Palgrave Macmillan, 2018. ISBN 978-3-319-69352-1.

BRAUTIGAM, Debora. The Dragon's Gift: The Real Story of China in Africa. Oxford: Oxford University, 2011. ISBN 978-0-19-955022-7

CARMODY, Pádraig. The New Scramble for Africa. Cambridge: Polity Press, 2011. ISBN 9781509507078.

OLIVER, August. A Hopeful Continente. The Economist. Mar 2nd 2013. Disponível em: $\quad<$ https://www.economist.com/special-report/2013/03/02/a-hopeful-continent $>$. Acesso em 20 de maio de 2020.

SHAMBAUGH, Debora. China Goes Global: The Partial Power. Oxford: Oxford University, 2014. ISBN: 978-019-986-0142.

TAYLOR, Ian. China's Oil Diplomacy in Africa. International Affairs, 82(5), 937959. Setembro. 2006. https://doi.org/10.1111/j.1468-2346.2006.00579.x

TAYLOR, Ian. The International Relations of Sub-Saharan Africa. New York: The Continuum International Publishing Group Inc, 2010. ISBN 978-0-8264-3490-6

TIFFEN, Adam. The New Neo-Colonialism in Africa. Global Policy Journal, 19 de Agosto de 2014. Disponível em: $<$ http://www.globalpolicyjournal.com/blog/19/08/2014/new-neo-colonialism-africa $>$. Acesso em 16 de junho de 2020. 